\title{
EVALUASI PENGENDALIAN RISIKO PT. LEMBAH KARET BERDASARKAN RISK REDUCTION
}

\author{
Esmiralda \\ Jurusan Teknik Lingkungan Universitas Andalas \\ Email: esmiralda@ft.unand.ac.id
}

\begin{abstract}
ABSTRAK
Penelitian ini bertujuan untuk mengevaluasi pengendalian risiko pada PT. X berdasarkan nilai Risk Reduction dan memberikan saran pengendalian yang paling tepat untuk mengatasi risiko tersebut. Metoda penelitian berupa studi literatur, analisis data primer dan sekunder dengan teknik pengumpulan data primer berupa observasi dan kuesioner. Penelitian dilakukan pada 3 (tiga) unit operasi yaitu Unit Pencacahan, Unit Penggilingan, dan Unit Penimbangan \& Penempaan. Diperoleh bahwa nilai Risk Reduction rata-rata PT. X sebesar 56,94\%. Kondisi ini memperlihatkan bahwa pengendalian yang telah diterapkan mampu menurunkan nilai risiko sampai dengan setengah dari kondisi awal tanpa adanya pengendalian. Upaya pengendalian yang dapat dilakukan agar risiko dapat dihilangkan atau nilai Risk Reduction mencapai $100 \%$ antara lain melakukan pengendalian administratif, pengendalian engineering, dan penggunaan APD.
\end{abstract}

Kata kunci: Risk Reduction, PT. X, Pengendalian Administratif, Pengendalian Engineering, APD

\begin{abstract}
This research was aimed to evaluate the risk control of PT. X with Reduction Risk and give the solutions for control the risk. The research methods were literature study, analysis primary data and secondary data with observation and quisioner. Three operation units of PT. X that observed were enumeration unit, creeping unit, and weighing \& pressing unit. The average Risk Reduction value of PT. X were 56,94\%. It showed that the controlled methods were able to reduced the risks until a half of it. The controlled methods to eliminate the risks are administrative control, engineering control, and personal protective equipment (PPE.)
\end{abstract}

Keywords: Risk Reduction, PT. X, Administrative Control, Engineering Control, PPE 


\section{PENDAHULUAN}

Perkembangan industri yang semakin pesat berkorelasi dengan semakin banyaknya tenaga kerja yang dibutuhkan untuk mendukungnya. Dampak positif perkembangan industri selain membuka lapangan pekerjaan juga sebagai penghasil produk-produk yang dibutuhkan oleh manusia untuk menunjang kehidupan. Selain dampak positif, dampak negatif yang ditimbulkan oleh industri berupa pencemaran lingkungan, penyakit kerja, dan kecelakaan kerja apabila tidak ada sistem yang mengelola hal tersebut dengan baik oleh pihak perusahaan. Kewajiban tentang adanya Sistem Manajemen Keselamatan dan Kesehatan Kerja (SMK3) pada suatu perusahaan dengan kriteria tertentu menjadi suatu tolok ukur bagi kinerja sebuah perusahaan terhadap keselamatan dan kesehatan pekerjanya. Sikap kritis dari masyarakat juga mendorong industri yang berisiko terhadap pekerja untuk menerapkan suatu sistem pengelolaan yang aman bagi pekerjanya.

Kewajiban untuk menyelenggarakaan SMK3 pada perusahaan-perusahaan besar melalui UU Ketenagakerjaan, baru menghasilkan 2,1\% saja dari 15.000 lebih perusahaan berskala besar di Indonesia yang sudah menerapkan SMK3. Minimnya jumlah tersebut sebagian besar disebabkan oleh masih adanya anggapan bahwa program K3 hanya akan menjadi tambahan beban biaya perusahaan. Padahal jika diperhitungkan besarnya dana kompensasi/ santunan untuk korban kecelakaan kerja sebagai akibat diabaikannya SMK3 mencapai lebih dari 190 milyar rupiah di tahun 2003, sehingga jelaslah bahwa masalah K3 tidak selayaknya diabaikan (Kolluru, 1996). Angka kecelakaan kerja di Indonesia tahun 2011, menurut Menteri
Tenaga Kerja sebanyak 96.314 kasus kecelakaan kerja di mana 2.144 orang meninggal dunia dan 42 orang mengalami cacat akibat kecelakaan kerja dan sisanya mengalami luka serius hingga luka ringan.

Kecelakaan adalah kejadian yang tak terduga dan tidak diharapkan dimana dalam peristiwa tersebut tidak terdapat unsur kesengajaan, terlebih lagi dalam bentuk perencanaan. Kecelakaan dapat menghambat pembangunan proyek, kerugian materi, kehilangan waktu, kecacatan yang dapat menurunkan kualitas hidup pekerja bahkan kematian. Kecelakaan kerja adalah suatu kejadian atau peristiwa yang tidak diinginkan yang merugikan terhadap manusia, merusak harta benda atau kegiatan terhadap proses (Budiono dan Pusparini, 2003).

PT. X sebagai salah satu perusahaan pengolahan karet terbesar di Sumatera Barat telah memiliki SMK3 dengan visi berusaha mencapai "zero accident" dalam bentuk upaya pencegahan dan mengurangi terjadinya kasus kecelakaan kerja. Guna mendukung visi tersebut maka salah satu upaya yang dapat dilakukan berupa evaluasi pengendalian risiko keselamatan kerja berdasarkan nilai Risk Reduction. Dimana nilai ini menggambarkan besarnya risiko yang dapat dikurangi oleh PT. X dengan metoda pengendalian eksisting yang telah dilakukan.

\section{METODOLOGI}

Metoda penelitian berupa studi literatur, analisis data primer dan sekunder. Teknik pengumpulan data primer berupa observasi dan kuesioner. Observasi dilakukan dengan cara peninjauan langsung terhadap proses kerja serta peralatan yang 
digunakan yang dapat menyebabkan terjadinya risiko terhadap keselamatan pekerja. Observasi ini juga meliputi wawancara tidak terstruktur kepada manager produksi, bagian laboratorium, bagian administrasi, pengawas lapangan dan beberapa pekerja. Kuesioner diambil sebanyak 20 buah untuk setiap unit kerja dengan total keseluruhan pada ketiga unit menjadi 60 buah kuisioner. Jumlah ini secara statistik akan dapat terdistribusi normal karena syarat minimal data agar dapat terdistribusi normal adalah minimal 30 buah. Data sekunder berupa data yang diperoleh dari PT. X seperti: profil perusahaan, proses produksi, jam kerja karyawan dan data kecelakaan selama 10 tahun (2002-2011).

Analisis risiko dilakukan untuk memperkirakan risiko dengan mengkombinasikan faktor probabilitas dan konsekuensi. Metode yang dipakai dalam analisis risiko adalah metode semikuantitatif. Kemudian dilakukan penilaian terhadap risiko tersebut secara matematis menggunakan metode Fine. Persamaan WT. Fine:

$$
\mathrm{RR}=\mathrm{P} \times \mathrm{E} \times \mathrm{C}
$$

Dimana:

RR : Risk Rating / Nilai Risiko

$$
\begin{array}{ll}
\mathrm{P} & \text { : Probability / Peluang } \\
\mathrm{E} & \text { : Exposure / Paparan } \\
\mathrm{C} & \text { : Consequence / }
\end{array}
$$

Konsekuensi

Evaluasi risiko menggunakan Risk Reduction dilakukan untuk melihat efisiensi pengendalian terhadap risiko dilingkungan kerja yang telah dilakukan oleh perusahaan. Risk Reduction adalah persentase risiko yang dapat dikurangi oleh perusahaan dengan pengendalian yang diterapkan dihitung dengan formula:
Risk Reduction $=\left(\frac{\text { Basic Level }- \text { Existing Level }}{\text { Basic Level }}\right) \times 100 \%$

Basic level yaitu nilai risiko terparah yang mungkin terjadi apabila tanpa ada pengendalian. Sedangkan nilai risiko pada existing level adalah nilai risiko yang dihitung setelah dilakukan pengendalian. Untuk lebih jelasnya metodologi penelitian dapat dilihat pada Gambar 1.

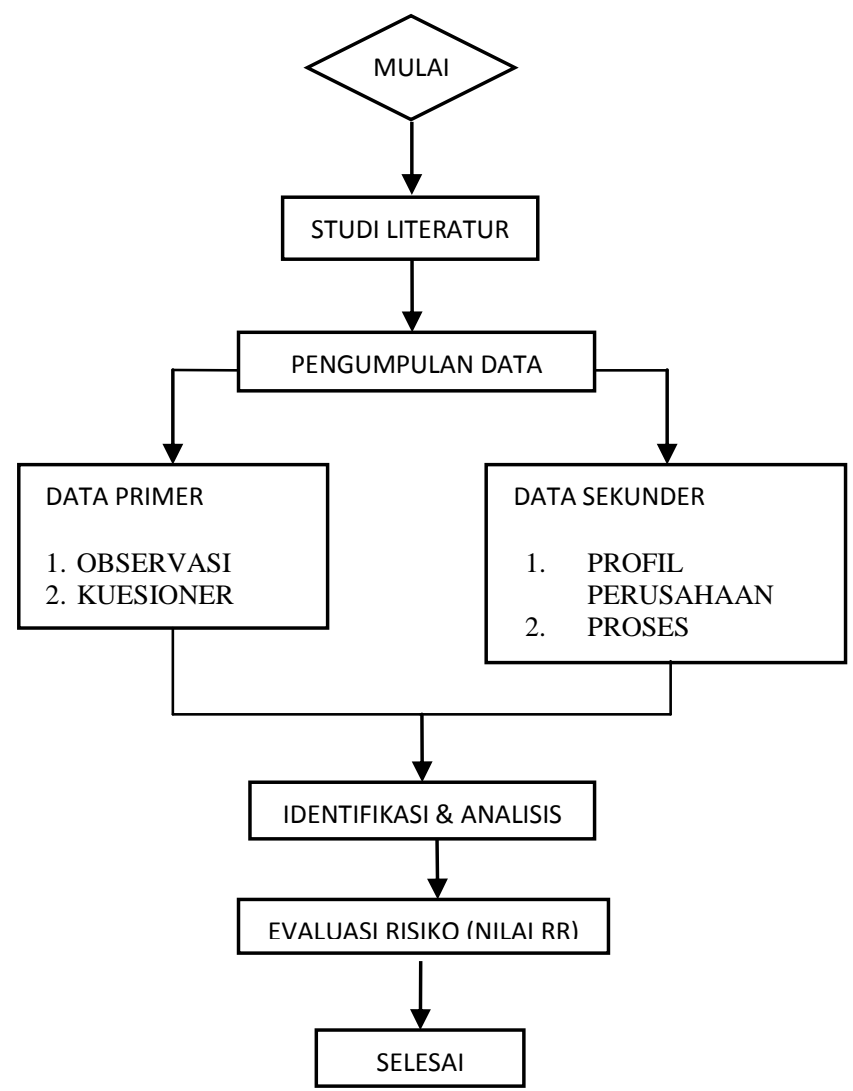

Gambar 1. Diagram Alir Metodologi Penelitian

\section{HASIL DAN PEMBAHASAN}

Berdasarkan analisis risiko pada penelitian yang dilakukan oleh Melissa (2013) pada PT. X diketahui bahwa Basic Level berada pada rentang 20 - 1500 dan Existing Level berada pada rentang 1 - 900. Berdasarkan Tabel 1, diketahui bahwa Risk Reduction rata-rata PT. X sebesar 56,94\%. Hal ini memperlihatkan bahwa pengendalian yang dilakukan oleh industri masih dapat 
ditingkatkan sampai dengan 100\%. Pada unit-unit tertentu terlihat nilai Risk Reduction masih berada dibawah 50\% bahkan $0 \%$. Berikut ini akan diuraikan mengenai risiko dan pengendalian yang telah dilakukan PT. X pada masing-masing unit kerja.

\section{Unit Pencacahan}

Risiko terhadap keselamatan pekerja pada unit pencacahan berupa terpeleset, tergores, terjatuh, tertabrak forklift, dan tertabrak bucket transfer mempunyai nilai Risk Reduction di atas $60 \%$. Hal ini berarti bahwa upaya pengendalian yang telah dilakukan oleh PT. $X$ telah mampu menurunkan risiko kecelakaan yang terjadi. Sedangkan untuk risiko kecelakaan lalu lintas dan tertindih forklift memiliki nilai Risk Reduction sebesar 33,3\% dan $40 \%$. Nilai ini mengindikasikan bahwa usaha pengendalian yang telah dilakukan oleh PT. X belum mampu menurunkan nilai risiko secara maksimal. Gambaran nilai Risk Reduction untuk setiap risiko pada unit pencacahan dapat dilihat pada Gambar 2

Pengendalian yang telah dilakukan untuk menurunkan risiko kecelakaan lalu lintas berupa pengaturan shift kerja dan rotasi pekerja agar pekerja tidak mengalami kelelahan yang dapat memicu terjadinya risiko. Untuk meningkatkan nilai Risk Reduction disarankan agar pengaturan shift kerja juga mempertimbangkan usia. Dimana semakin tua usia pekerja maka beban kerja atau jam kerja semakin dikurangi.

Pengendalian risiko tertindih forklift eksisting berupa adanya Standar Operational Procedure (SOP) penggunaan forklift dan pelatihan bekerja secara aman sekali dalam setahun. Upaya pengendalian tambahan yang dapat dilakukan agar risiko berkurang adalah dengan memberikan izin khusus bagi pengendara forklift (bersertifikat) dan sosialisasi serta pelatihan bekerja yang aman secara rutin minimal 2 kali dalam setahun.

Tabel 1. Nilai Risiko dan Risk Reduction

\begin{tabular}{|c|c|c|c|c|}
\hline \multirow[b]{2}{*}{ No } & \multirow[b]{2}{*}{ RISIKO } & \multicolumn{2}{|c|}{ NILAI RISIKO } & \multirow{2}{*}{$\begin{array}{r}\text { Risk } \\
\text { Red } \\
(\%)\end{array}$} \\
\hline & & $\begin{array}{l}\text { BASIC } \\
\text { LEVEL }\end{array}$ & $\begin{array}{c}\text { EKSISTING } \\
\text { LEVEL }\end{array}$ & \\
\hline \multirow[t]{8}{*}{1} & \multicolumn{4}{|l|}{ UNIT PENCACAHAN } \\
\hline & A. Terpeleset & 18 & 5 & 72.2 \\
\hline & B. Tergores & 36 & 1 & 97.2 \\
\hline & C. Terjatuh & 18 & 0.5 & 97.2 \\
\hline & D. Kecelakaan lalu lintas & 225 & 150 & 33.3 \\
\hline & E. Tertabrak forklift & 150 & 15 & 90.0 \\
\hline & F. Tertindih forklift & 225 & 135 & 40.0 \\
\hline & $\begin{array}{l}\text { G. Tertabrak bucket } \\
\text { transfer }\end{array}$ & 45 & 15 & 66.7 \\
\hline \multirow[t]{5}{*}{2} & \multicolumn{4}{|l|}{ UNIT PENGGILINGAN } \\
\hline & A. Terluka & 270 & 135 & 50.0 \\
\hline & $\begin{array}{l}\text { B. Terjatuh, terlindas } \\
\text { mesin }\end{array}$ & 900 & 540 & 40.0 \\
\hline & C. Terjatuh dari lift & 900 & 900 & 0.0 \\
\hline & $\begin{array}{l}\text { D. Tertabrak bucket } \\
\text { transfer }\end{array}$ & 30 & 15 & 50.0 \\
\hline \multirow[t]{8}{*}{3} & \multicolumn{4}{|c|}{ UNIT PENIMBANGAN DAN PENEMPAAN } \\
\hline & A. Tertimpa gancu & 45 & 15 & 66.7 \\
\hline & B. Terbentur & 20 & 10 & 50.0 \\
\hline & C. Terjatuh & 150 & 25 & 83.3 \\
\hline & D. Luka bakar & 1500 & 900 & 40.0 \\
\hline & E. Tertimpa cake karet & 900 & 15 & 98.3 \\
\hline & F. Terluka & 900 & 900 & 0.0 \\
\hline & G. Terjepit mesin press & 250 & 125 & 50.0 \\
\hline
\end{tabular}

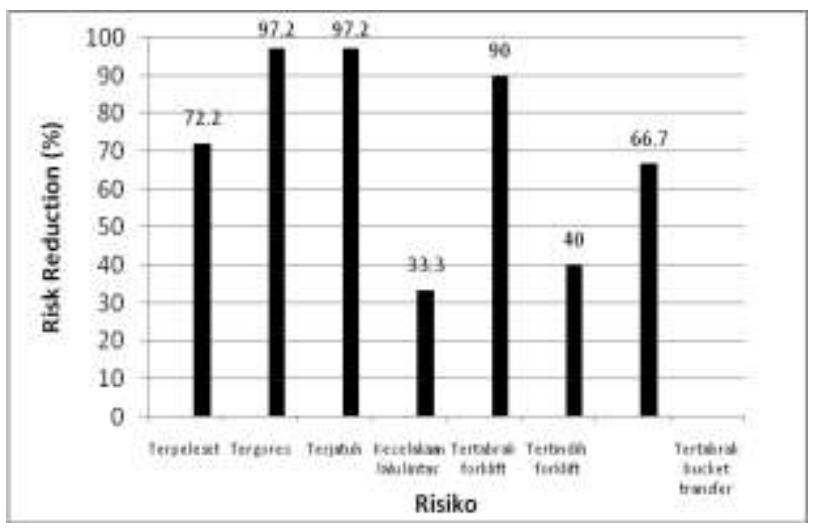

Gambar 2. Risk Reduction Risiko Unit Pencacahan 


\section{Unit Penggilingan}

Risiko keselamatan pekerja pada unit penggilingan berupa terluka, kaki terlindas mesin, terjatuh dari lift dan tertabrak bucket transfer mempunyai nilai Risk Reduction berturut-turut sebesar $50 \%$, 40\%, 0\%, dan 50\% (Gambar 3). Terlihat bahwa upaya pengendalian eksisting masih belum bisa menurunkan risiko hingga $100 \%$.

Upaya pengendalian yang telah dilakukan oleh PT. X berupa pelatihan bekerja secara aman sesuai SOP sekali dalam setahun. Berdasarkan observasi di lapangan terlihat bahwa penggunaan APD masih sangat minim karena masih rendahnya kesadaran pekerja terhadap bahaya/risiko yang ada. Selain itu ketersediaan APD yang memenuhi standar juga tidak mencukupi. Pengendalian yang disarankan antara lain penggunaan sepatu safety dan memberi jaring pengaman di area kerja dengan ketinggian ekstrem untuk mengurangi risiko terjatuh dari lift. Pemasangan rambu peringatan bahaya tertabrak bucket transfer pada unit penggilingan, sosialisasi dan pelatihan bekerja yang aman secara rutin (minimal 2 kali setahun) diharapkan dapat meningkatkan nilai Risk Reduction pada unit ini.

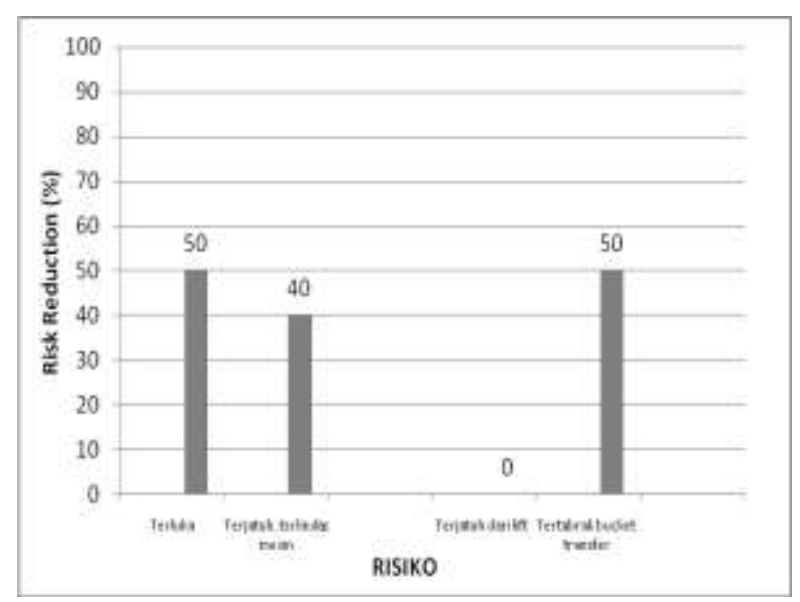

Gambar 3. Risk Reduction Risiko Unit Penggilingan

\section{Unit Penimbangan dan Penempaan}

Risiko terbentur, luka bakar, terluka karena pisau potong karet dan terjepit mesin press pada unit ini masih cukup rendah yaitu dibawah angka 50\% (Gambar 4). Saat ini belum ada upaya pengendalian yang telah dilakukan oleh perusahaan untuk dapat mengurangi risiko yang terjadi.

Untuk meminimalkan atau menghilangkan risiko yang terjadi, pengendalian dapat berupa melengkapi APD seperti helm, sarung tangan dan memberikan pelatihan serta motivasi bagi pekerja agar dapat menerapkan SOP yang ada. Sedangkan risiko tertimpa gancu, terjatuh, dan tertimpa cake karet mempunyai nilai Risk Reduction diatas 50\%, menandakan pengendalian yang dilakukan telah cukup baik.

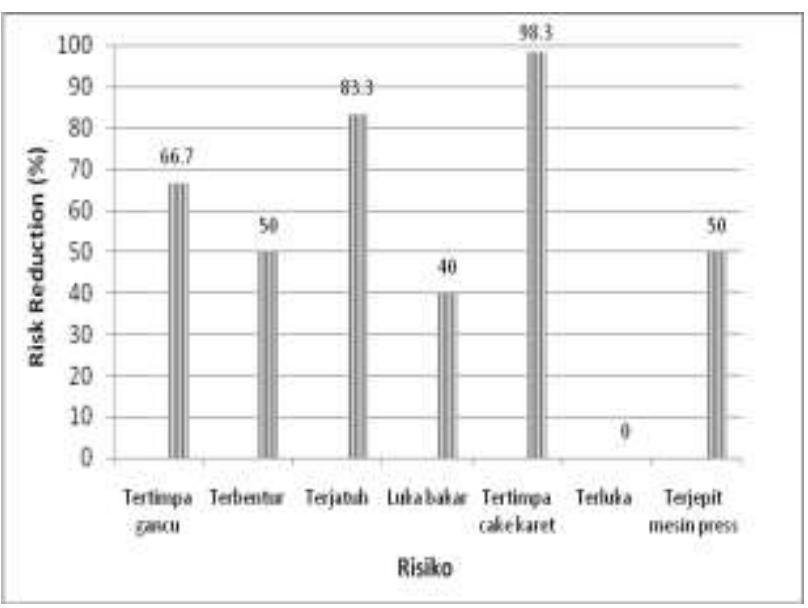

Gambar 4. Risk Reduction Risiko Unit Penimbangan dan Penempaan

Walaupun beberapa risiko telah memberikan nilai Risk Reduction yang cukup besar bukan berarti pengendalian tidak perlu diperhatikan lagi. Pengendalian harus tetap dilakukan secara konsisten dan diawasi agar risiko yang ada benar-benar dapat dihilangkan. Rekapitulasi pengendalian yang dapat dilakukan pada 
PT. X untuk meminimalkan risiko yang terjadi dapat dilihat pada Tabel 2.

Berdasarkan hasil evaluasi risiko diatas, maka pengendalian yang dapat dilakukan guna meningkatkan nilai Risk Reduction di kelompokkan dalam:

\section{Pengendalian administratif}

Prinsipnya mengurangi kontak antara penerima dan sumber risiko/bahayaseperti:

- Mencegah pekerja dari kejenuhan, kelelahan dan kebosanan dengan cara mengontrol jam kerja pekerja/pergantian shift kerja serta rotasi pekerja;

- Memberikan penyuluhan kepada pekerja tentang pentingnya bekerja aman dan selamat bagi pekerja dan perusahaan;

Tabel 2. Rekapitulasi Pengendalian Risiko

\begin{tabular}{|c|c|c|}
\hline No. & Risiko & Pengendalian yang disarankan \\
\hline 1. & \multicolumn{2}{|l|}{ UNIT PENCACAHAN } \\
\hline & $\begin{array}{l}\text { A. Kecelakaan lalu } \\
\text { lintas }\end{array}$ & $\begin{array}{l}\text { - Pengaturan Shift Kerja sesuai usia dan rotasi } \\
\text { pekerja }\end{array}$ \\
\hline & B. Tertindih forklift & $\begin{array}{l}\text { - Sosialisasi dan pelatihan bekerja secara aman } \\
\text { (minimal } 2 \text { kali dalam setahun) } \\
\text { - Pengendara forklift mempunyai izin khusus } \\
\text { - Memberi pagar pembatas di area perlintasan } \\
\text { forklift }\end{array}$ \\
\hline 2. & \multicolumn{2}{|c|}{ UNIT PENGGILINGAN } \\
\hline & A. Terluka & \multirow{4}{*}{$\begin{array}{l}\text { - Sosialisasi dan pelatihan bekerja secara aman } \\
\text { sesuai SOP minimal dua kali dalam setahun } \\
\text { - Pemasangan rambu peringatan bahaya dan } \\
\text { rambu penggunaan APD } \\
\text { - Penyediaan APD sesuai standar (safety } \\
\text { hemet, safety shoes, leather gloves) }\end{array}$} \\
\hline & $\begin{array}{l}\text { B. Terjatuh, terlindas } \\
\text { mesin }\end{array}$ & \\
\hline & C. Terjatuh dari lift & \\
\hline & $\begin{array}{l}\text { D. Tertabrak bucket } \\
\text { transfer }\end{array}$ & \\
\hline 3. & \multicolumn{2}{|c|}{ UNIT PENIMBANGAN DAN PENEMPAAN } \\
\hline & A. Terbentur & \multirow{4}{*}{$\begin{array}{l}\text { - Sosialisasi dan pelatihan bekerja secara aman } \\
\text { sesuai SOP minimal dua kali dalam setahun } \\
\text { - Pemasangan rambu peringatan bahaya dan } \\
\text { rambu penggunaan APD } \\
\text { - Penyediaan APD sesuai standar (safety } \\
\text { hemet, safety shoes, leather gloves) }\end{array}$} \\
\hline & B. Luka bakar & \\
\hline & C. Terluka & \\
\hline & $\begin{array}{l}\text { D. Terjepit mesin } \\
\text { press }\end{array}$ & \\
\hline
\end{tabular}

- Menugaskan tim pengawas khusus dari perusahaan untuk mengawasi pekerja ketika melakukan pekerjaan yang berisiko terhadap keselamatan;

- Memberi pelatihan penggunaan mesin dan peralatan yang aman;
- Memberi pelatihan tanggap darurat jika terjadi kecelakaan secara berkala dari perusahaan;

- Memberi rambu peringatan untuk memakai alat pelindung diri (APD), ada alat/mesin yang berbahaya (untuk lokasi tertentu) dan larangan untuk masuk ke lokasi power listrik.

\section{Pengendalian engineering}

Prinsipnya merubah jalur transmisi bahaya atau mengisolasinya. Hal ini dapat dilakukan dengan cara:

- Memberi pagar pembatas di sekitar perlintasan forklift untuk mencegah pekerja lain melintas ketika forklift melaju;

- Memberi bantalan (alat peredam bising) pada mesin-mesin yang menghasilkan kebisingan sehingga pekerja tidak kesulitan ketika menerima informasi apapun saat sedang bekerja.

\section{Alat Pelindung Diri (APD)}

Berfungsi untuk mengurangi tingkat keparahan risiko suatu bahaya terhadap manusia. APD yang dapat digunakan berdasarkan risiko yang terjadi antara lain:

a. Bahaya terpeleset

Bahaya terpeleset dapat dihindari dengan memakai safety shoes/ sepatu anti slip saat bekerja pada proses basah dan berada pada lingkungan kerja yang berisiko terpeleset.

b. Bahaya tertimpa

Alat pelindung diri dari bahaya tertimpa dapat berupa penggunaan safety helmet kelas A.

c. Bahaya tergores atau terluka 
Bahaya tergores dan terluka pada tangan dapat dihindari dengan penggunaan APD sarung tangan jenis leather gloves.

\section{SIMPULAN}

Risiko-risiko yang dapat membahayakan keselamatan pekerja di PT. X pada unit Pencacahan berupa terpeleset, tergores, terjatuh, kecelakaan lalu lintas, tertabrak forkflit, tertindih forklift, dan tertabrak bucket transfer; pada unit Penggilingan risiko berupa terluka, terjatuh, terlindas mesin mangle, terjatuh dari lift, dan tertabrak bucket transfer; dan pada unit Penimbangan \& Penempaan berupa tertimpa gancu, terbentur, terjatuh, luka bakar, tertimpa cake karet, terluka, dan terjepit mesin press.

Upaya pengendalian yang dilakukan PT. X dalam mengatasi risiko-risiko yang terjadi masih cukup rendah, hal ini terlihat dari nilai Risk Reduction rata-rata sebesar $56,94 \%$. Pengendalian yang dilakukan agar nilai Risk Reduction mencapai 100\% antara lain berupa pengendalian administratif, pengendalian secara teknis dan penggunaan APD secara menyeluruh di seluruh unit yang ada.

\section{DAFTAR PUSTAKA}

AS/NZS 4360-1999. Risk Management Guidelines. Sydney: 1999.

AS/NZS 4360- 2004. The Australia and New Zealand Standard on Risk Management. Broadleaf Capital International Pty Ltd, NSW Australia: 2004.

Budiono, S dan Jusuf Pusparini. Bunga Rampai HIPERKES dan Kesehatan Kerja. Semarang, UNDIP., 2003.

Indonesia. Kementerian Tenaga Kerja. Peraturan Menteri Tenaga Kerja No. 05/Menaker/Per/1996. tentang Sistem Manajemen Keselamatan dan Kesehatan Kerja. Jakarta: Kemenaker, 1996.

Indonesia. Undang- undang Republik Indonesia Nomor 01. 1970 tentang Keselamatan Kerja. Jakarta, 1970.

Kolluru, Rao V, et. al. Risk Assessment and Management Handbook. New York: Mc Graw Hill Inc., 1996.

Melissa, Penilaian Risiko di Lingkungan

Kerja terhadap Keselamatan Pekerja PT. Lembah Karet. Tugas

Akhir., Universitas Andalas Padang, (2013)

Notoatmodjo, Soekidjo. Pendidikan Dan Perilaku Kesehatan. Jakarta: Rineka Cipta., 2003.

OSHA 3151-2000. Assesing The Need for Personal Protective Equipment. US of Department Labor of Occupational Safety and Health Administration: 2000.

Wentz, C.A. Safety Health and Environmental Protection. Boston: Mc Graw Hill., 1999. 